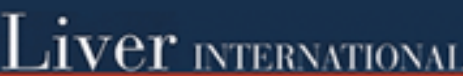

\section{Hepatitis C virus eradication by direct antiviral agents abates oxidative stress in patients with advanced liver fibrosis}

\begin{tabular}{|c|c|}
\hline Journal: & Liver International \\
\hline Manuscript ID & LIVint-20-00350.R1 \\
\hline Wiley - Manuscript type: & Original Articles \\
\hline $\begin{array}{r}\text { Date Submitted by the } \\
\text { Author: }\end{array}$ & 07-Jun-2020 \\
\hline Complete List of Authors: & $\begin{array}{l}\text { Salomone, Federico; Azienda Sanitaria Provinciale di Catania, Division of } \\
\text { Gastroenterology, Ospedale di Acireale } \\
\text { Petta, Salvatore; Cattedra ed Unità Operativa Complessa di } \\
\text { Gastroenterologia, Dipartimento Biomedico di Medicina Interna e } \\
\text { Specialistica } \\
\text { Micek, Agnieszka; Uniwersytet Jagiellonski w Krakowie Collegium } \\
\text { Medicum, Epidemiology and Population Studies } \\
\text { Pipitone, Rosaria Maria; University of Palermo, Promise } \\
\text { Distefano, Alfio; University of Catania, Biometec } \\
\text { Castruccio Castracani, Carlo; University of Catania, Biomedical and } \\
\text { biotechnological sciences } \\
\text { Rini, Francesca; University of Palermo, Gastroenterologia \& Epatologia, } \\
\text { PROMISE } \\
\text { Di Rosa, Michelino; University of Catania, Biomedical and } \\
\text { biotechnological sciences } \\
\text { Gardi, Concetta; University of Siena, Molecular and development } \\
\text { medicine } \\
\text { Calvaruso, Vincenza; University of Palermo, Gastroenterology } \\
\text { Di Marco, Vito; University of Palermo, Section of Gastroenterology, } \\
\text { DIBIMIS } \\
\text { Li Volti, Giovanni; University of Catania, Drug Sciences } \\
\text { Grimaudo, Stefania; Universita degli Studi di Palermo, Section of } \\
\text { Gastroenterology, Di.Bi.M.I.S. } \\
\text { Craxi, Antonio; University of Palermo, Sezione di Gastroenterologia, } \\
\text { Dipartimento Biomedico di Medicina Interna e Specialistica }\end{array}$ \\
\hline Keywords: & HCV, Oxidative stress, Fibrosis, Lipid peroxidation \\
\hline
\end{tabular}

\section{SCHOLARONE"




\section{Hepatitis C virus eradication by direct antiviral agents abates oxidative stress in patients with advanced liver fibrosis}

Federico Salomone ${ }^{1 * \#}$, Salvatore Petta ${ }^{2 \#}$, Agnieszka Micek $^{3}$, Rosaria Maria Pipitone ${ }^{2}$, Alfio Distefano $^{4}$, Carlo Castruccio Castracane ${ }^{4}$, Francesca Rini ${ }^{2}$, Michelino Di Rosa ${ }^{4}$, Concetta Gardi $^{5}$, Vincenza Calvaruso², Vito Di Marco², Giovanni Li Volti ${ }^{4}$, Stefania Grimaudo ${ }^{2 \#}$ and Antonio Craxi ${ }^{2 \#}$

${ }^{1}$ Division of Gastroenterology, Ospedale di Acireale, Azienda Sanitaria Provinciale di Catania, Catania, Italy; ${ }^{2}$ Section of Gastroenterology and Hepatology, PROMISE, University of Palermo, Palermo, Italy; ${ }^{3}$ Department of Nursing Management and Epidemiology Nursing, Jagiellonian University Medical College, Krakow, Poland. ${ }^{4}$ Department of Biomedical and Biotechnological Sciences, University of Catania, Catania, Italy; ${ }^{5}$ Department of Molecular and Developmental Medicine, University of Siena, Siena, Italy

\#Equal contribution

${ }^{*}$ Corresponding author:

Dr. Federico Salomone

Azienda Sanitaria Provinciale di Catania

Via Santa Maria La Grande, 5

95124 Catania, Italy

Tel.: + 393206990366

Email: federicosalomone@rocketmail.com

Financial support: Research grants from the University of Palermo and the University of Catania

Conflict of interest: nothing to disclose for all authors

Tables: 4 Figures: 2 Suppl. Tables: 3 Word count: 3460

Keywords (not in the title):

atherosclerosis, cirrhosis, $F_{2}$-isoprostanes, intima-media thickness, lipid peroxidation

\section{LAY SUMMARY}

-HCV eradication improves atherosclerosis although without clearly defined mechanisms

-We hypothesized that reduction of oxidative stress, as measured by serum $\mathrm{F}_{2^{-}}$ isoprostanes, may be involved in the improvement of atherosclerosis after $\mathrm{HCV}$ eradication

-We demonstrated that the reduction of carotid intima-media thickness after viral clearance is directly and independently associated with the reduction of circulating $F_{2}$-isoprostanes 


\section{ABSTRACT}

Background and aims. HCV eradication improves non-hepatic outcomes such as cardiovascular diseases although without clearly defined mechanisms. In this study we aimed to assess whether improvement of carotid atherosclerosis may be linked to a reduction of systemic oxidative stress after viral clearance.

Methods. We studied a retrospective cohort of 105 patients (age $62.4 \pm 11.2$ years; 62 males) with F3/F4 fibrosis, characterized by carotid ultrasonography at baseline and at sustained virologic response (SVR) follow-up. Levels of 8-iso-prostaglandin $F_{2 a}\left(F_{2^{-}}\right.$ isoprostanes) and other oxidative stress markers were measured on frozen sera. Association between change (denoted as $\Delta$ ) of oxidative stress markers (exposures) and change of carotid intima-media thickness (cIMT) (outcome) was examined using multiple linear regression.

Results. Subclinical atherosclerosis, defined as the presence of carotid plaque and/or CIMT $\geq 0.9$, was present in $72 \%$ of the cohort. All patients achieved SVR that led to reduction of cIMT $(0.92 \pm 0.20$ vs $0.83 \pm 0.21 \mathrm{~mm}, \mathrm{P}<0.001)$. HCV eradication markedly decreased serum levels of $F_{2}$-isoprostanes (620.5 [143.2; 1904.1] vs 119.51 [63.2; 400.6] $\mathrm{pg} / \mathrm{ml}, \quad \mathrm{P}<0.0001)$, lipid hydroperoxides $(13.8[6.3 ; 20.7]$ vs $4.9[2.3 ; 9.6] \mathrm{nmol} / \mu \mathrm{l}$, $\mathrm{P}<0.0001)$ and 8-hydroxy-2'-deoxyguanosine (558.9 [321.0; 6301.2] vs 294.51 [215.31; 408.95] pg/ml, $P<0.0001)$ whereas increased serum GPx activity $(10.44$ [4.6; 16.3] vs $13.75[9.42 ; 20.63] \mathrm{nmol} / \mathrm{min} / \mathrm{ml}, \mathrm{P}=0.001)$. By multiple linear regression analysis $\Delta \mathrm{cIMT}$ was independently associated with $\Delta \mathrm{F}_{2}$-isoprostanes $(\beta: 1.746[0.948 ; 2.543] ; \mathrm{P}<0.0001)$ after adjustment for age, baseline $\mathrm{F}_{2}$-isoprostanes and baseline IMT.

Conclusions. Besides association of lipid peroxidation with severity of liver disease, the reduction of $\mathrm{F}_{2}$-isoprostanes may be involved in the improvement of atherosclerosis after HCV eradication. 


\section{INTRODUCTION}

Hepatitis $\mathrm{C}$ virus (HCV) chronic infection affects about 70 million of individuals worldwide with an estimated global prevalence of $1.0 \%$ widely changing according to geographical areas ${ }^{1}$. This epidemiological scenario is clinically relevant because chronic hepatitis $\mathrm{C}$ $(\mathrm{CHC})$ is associated with liver-related morbidity and mortality, but also with extrahepatic complications such as insulin resistance ${ }^{2,3}$ and cardiovascular diseases ${ }^{4}$. The availability of safe and effective direct antiviral agents (DAA) is currently showing us the impact of HCV eradication on hepatic and non-hepatic outcomes 5 although the molecular mechanisms that underlie the protective effects of HCV clearance against cardiovascular events ${ }^{6}$ remain to be fully elucidated.

Oxidative stress indicates an imbalance between reactive oxygen species (ROS) production and ability of a biological system to counteract ROS damage to cells and organs ${ }^{7}$. Oxidative stress can be triggered by several noxae including viruses and bacteria ${ }^{8}$. It is a common opinion that although increased levels of ROS have a beneficial effect in counteracting infections in the acute phase, establishment of a chronic infection may induce oxidative stress leading to cell damage and organ dysfunction . Increased ROS production targets various intracellular macromolecules, leading to lipid peroxidation, protein oxidation and nucleic acid oxidative damage ${ }^{9}$.

Previous reports showed that HCV triggers oxidative stress in in vitro models of infection ${ }^{10}$ and clinical data have consistently suggested that oxidative stress is a feature of patients with $\mathrm{CHC}{ }^{11}$. To this regard, Valgimigli and colleagues measured ROS levels in HCVinfected liver samples demonstrating higher levels as compared to control and showed that ROS correlated with histological disease activity ${ }^{12,13}$. Unfortunately, ROS detection is technically difficult and therefore it is preferable the use of lipid, DNA/RNA and protein oxidation biomarkers in clinical studies 14. Among markers of oxidative stress, 8-isoprostaglandin $\mathrm{F}_{2 \alpha}\left(\mathrm{F}_{2}\right.$-isoprostanes $)$ are considered not only the most accurate marker of 
lipid peroxidation ${ }^{15}$ but signaling molecules that are involved both in liver fibrogenesis ${ }^{16}$ and atherogenesis ${ }^{17}$. For this reason, we hypothesize that the improvement of subclinical atherosclerosis ${ }^{18}$ that follow HCV eradication may be linked to the decrease of systemic oxidative stress and in particular to the reduction of circulating levels of proatherogenic mediators such as $\mathrm{F}_{2}$-isoprostanes. 


\section{METHODS}

\section{Patients}

For sample size calculation we considered our previous study assessing changes in carotid intima-media thickness (cIMT) in patients with advanced liver fibrosis, treated with DAA ${ }^{18}$; based on it, a sample of 105 would be sufficient to detect a decrease in carotid IMT with an $\alpha$ error of 0.05 and a statistical power of $0.9 .{ }^{18}$ Frozen sera were available for outpatients recruited between middle 2015 and early 2016 at the Gastroenterology and Hepatology Unit of the University of Palermo, that were characterized for carotid atherosclerosis. At the time of enrollment, the Italian Medicines Agency (Agenzia Italiana del Farmaco, AIFA) did not allow treatment of patients with a milder stage of hepatitis $\mathrm{C}$ or advanced cirrhosis (Child-Pugh B and C) and criteria of eligibility for DAA treatment were: F3 fibrosis, diagnosed by histology and/or by liver stiffness measurement ( $\geq 10$ to $\leq 12 \mathrm{KPa}$ by FibroScan); compensated Child A cirrhosis, diagnosed by histology and/or by LSM (>12 $\mathrm{KPa}$ ), and/or by clinical evidence of portal hypertension. Beyond AIFA criteria, additional exclusion criteria for our study were: 1) hepatocellular carcinoma; 2) liver disease of different or mixed etiology (i.e., excessive alcohol consumption, hepatitis $B$, autoimmune liver disease, Wilson's disease, hemochromatosis, a1-antitrypsin deficiency); 3) HIV infection; 4) treatment with hepatotoxic drugs; 5) active drug addiction. Patients were tested at baseline for HCV-RNA (real-time PCR COBAS TaqMan HCV Test v2.0 and Roche diagnostics, S.p.A Monza, Italy) and HCV genotype (Versant HCV Genotype 2.0 Assay LIPA, Siemens, Erlangen, Germany). HCV-RNA was repeated after 4 weeks of therapy, at the end of therapy, and 12 weeks after stopping treatment. Sustained virologic response (SVR) was defined as HCV-RNA undetectable after 12 weeks from the end of antiviral therapy.

Assessment of carotid atherosclerosis was performed by using a high-resolution B-mode ultrasonography equipped with a multifrequency linear probe. cIMT was measured as the 
difference between the first (intima lumen) interface and the second (media adventitia) interface on the far wall of the common carotid artery in a section free of plaque beginning $10 \mathrm{~mm}$ below their bifurcations and including the bifurcations for $10 \mathrm{~mm}$. In agreement with joint guidelines from the European Society of Hypertension and the European Society of Cardiology ${ }^{19}$, subclinical atherosclerosis was considered as the presence of asymptomatic carotid plaque (focal thickening $\geq 1.5 \mathrm{~mm}$ ) or cIMT $\geq 0.9 \mathrm{~mm}$ without plaque. IMT measurement was performed by the same operator at baseline and at follow-up. Imaging and clinical data were collected at the time of the enrollment and 9 months after the end of antiviral therapy.

The study was conducted in accordance with the principles of the Declaration of Helsinki and its appendices, and with local and national laws. Approval was obtained from the local Institutional Review Board and Ethics Committee, and written informed consent was obtained from all patients.

\section{Laboratory methods}

Measurement of a panel of oxidative stress parameters was performed on $-80{ }^{\circ} \mathrm{C}$ frozen serum samples that were collected before the beginning of DAA treatment (baseline) and 6 months after the end of DAA (SVR follow-up). Lipid peroxidation status was assessed by measuring levels of lipid hydroperoxides ( $\mathrm{LOOH}$ ) through a modified ferrous oxidation/xylenol orange assay, at $\lambda=560 \mathrm{~nm}$, as previously described 20 and by measuring levels of 8-epi-prostaglandin $F_{2 \alpha}\left(F_{2}\right.$-isoprostanes), the most represented isomer of the isoprostanes series, through an ELISA kit (\#516351 from Cayman Chemical, Ann Arbor, MI), according to manufacturer's instruction. Serum levels of thiol groups, containing predominantly reduced glutathione, were determined spectrophotometrically at $\lambda=412 \mathrm{~nm}$ by Ellman's reagent, as previously described (17). As marker to evaluate oxidative damage to nucleic acids we used an ELISA kit (\#589320 Cayman Chemical) that detects the three oxidized guanine species: 8-hydroxy-2'-deoxyguanosine from DNA, 8- 
hydroxyguanosine from RNA, and 8-hydroxyguanine from either DNA or RNA; to simplify we indicate this marker as $8-\mathrm{OHdG}$, that is the most common one ${ }^{21}$. Serum activity of glutathione peroxidase (GPx) was measured through a colorimetric assay (\#703102 Cayman Chemical), according to manufacturer's instruction. Protein oxidation/nitrosylation was assessed by measuring the biomarker 3-nitrityrosine (3-NT) ${ }^{22}$ through an ELISA kit (\#SKT-126 from StressMarq Biosciences, Victoria, Canada).

\section{Statistical analysis}

Statistical analysis was performed by GraphPad Prism 8 (GraphPad Software, CA). Continuous variables are presented as mean \pm SD or median IQR (interquartile range), based on data distribution, established by Shapiro normality test. Differences from baseline to follow-up were assessed by paired T test or Wilcoxon signed ranks test based on data distribution. Multivariable logistic regression analyses were performed to establish the association between oxidative stress parameters and the presence of esophageal varices, carotid plaque and $\mathrm{cIMT} \geq 0.9$ as dependent categorical variable. Multiple linear regression analysis was performed to assess the association between change (denoted as $\Delta$ ) of oxidative stress markers (exposures) and change of cIMT (outcome). If values of exposures showed non-normal distribution, log-transformed values were considered for logistic and linear regression analyses. Calibration and discrimination ability of logistic models were checked using the Hosmer-Lemeshow statistic. 


\section{RESULTS}

\section{General features of the study population}

The main features of the study population are showed in Table 1. Mean age was $62.4 \pm 11.2$ years, with a $59 \%$ of males (62/105). Among 105 patients, 53 had fibrosis F3, 52 had compensated cirrhosis (27 Child A, 25 Child B). Among the 52 patients with cirrhosis, 26 of them had small esophageal varices. The most prevalent genotypes were 1b (79/105) and 1a (12/105). Liver stiffness in the whole cohort was $12[10.1 ; 19.4] \mathrm{kPa}$. As concern metabolic features, $25 \%$ of patients (26/105) were overweight/obese; mean serum total cholesterol and triglycerides were in the normal range. Thirty percent of patients had arterial hypertension (32/105), 12\% had type 2 diabetes (13/105); 15\% were active smokers. Overall, subclinical atherosclerosis was present in $72 \%(76 / 105)$ of the cohort. All patients were treated with DAA as showed in Table 1, according to therapeutic schedules suggested by EASL guidelines available at the time of the enrollment ${ }^{23}$.

\section{Effects of HCV eradication on clinical parameters}

All patients achieved an SVR following DAA treatment. As showed in Table 2, HCV eradication reduced serum AST (46 [28.7; 74.5] vs $20[17 ; 26] \mathrm{U} / \mathrm{l}, \mathrm{P}<0.0001)$, ALT (58.5 [30; 89] vs 20 [14.7; 26.2] U/l, P<0.0001), and GGT (43.5 [27; 90.2] vs 21 [16.7; 34.7], $P<0.0001)$ whereas increased levels of platelets $\left(139 \pm 61\right.$ vs $\left.160 \pm 7210^{3} / \mu l, P<0.05\right)$ and albumin $(4.0[3.8 ; 4.2]$ vs $4.1[3.9 ; 4.3] \mathrm{mg} / \mathrm{dl}, \mathrm{P}<0.05)$. Total bilirubin and INR were unchanged. SVR led to a reduction of liver stiffness $(12[10.1 ; 19.4]$ vs $10.6[6.7 ; 17] \mathrm{kPa}$, $\mathrm{P}<0.0001)$ and IMT $(0.92 \pm 0.20$ vs $0.83 \pm 0.21 \mathrm{~mm}, \mathrm{P}<0.001)$. As concern metabolic parameters, we observed a slight but significant decrease in fasting glucose $(98$ [88; 108] vs $94[86.5 ; 104] \mathrm{mg} / \mathrm{dl}, \mathrm{P}<0.05)$ despite no change of body weight from baseline to SVR follow-up. HCV clearance also increased serum total cholesterol $(156 \pm 40$ vs $168 \pm 44$ $\mathrm{mg} / \mathrm{dl}, \mathrm{P}<0.05)$ and triglycerides $(85.1 \pm 32 \mathrm{vs} 94.0 \pm 40.5 \mathrm{mg} / \mathrm{dl}, \mathrm{P}<0.05)$, although values remained in the normal range. 


\section{Effects of HCV eradication on oxidative stress parameters}

Changes in serum levels of oxidative stress markers are showed in Figure 1. As concern lipid peroxidation parameters, we found that serum $F_{2}$-isoprostanes levels were markedly reduced at follow-up after viral treatment (620.5 [143.2; 1904.1] vs 119.51 [63.2; 400.6] $\mathrm{pg} / \mathrm{ml}, \mathrm{P}<0.0001)$. Decrease of serum $\mathrm{F}_{2}$-isoprostanes was widely observed across subgroups discriminated according to stage of fibrosis and metabolic parameters. Specifically, $\mathrm{F}_{2}$-isoprostanes were reduced by $\mathrm{HCV}$ eradication in patients with $\mathrm{F} 3$ or $\mathrm{F} 4$, with normal or impaired fasting glucose and independently of BMI (Suppl. Table 1). In agreement with abatement of $\mathrm{F}_{2}$-isoprostanes levels, $\mathrm{HCV}$ eradication markedly decreased serum $\mathrm{LOOH}$ (13.8 [6.3; 20.7] vs 4.9 [2.3; 9.6] nmol/ $\mu \mathrm{l}, \mathrm{P}<0.0001)$ (Figure 1). For both markers of lipid peroxidation, reduction from baseline to SVR was greater in patients with cirrhosis (Suppl. Table 1). By simple linear regression, $F_{2}$-isoprostanes were associated with $\mathrm{LOOH}$ at baseline $(r=0.670, P<0.0001)$ and SVR $(r=0.490, P<0.0001)$.

As concern the antioxidant status, serum GPx activity was significantly higher at SVR compared to baseline $(10.44[4.6 ; 16.3]$ vs $13.75[9.42 ; 20.63] \mathrm{nmol} / \mathrm{min} / \mathrm{ml}, \mathrm{P}=0.001)$ (Figure 1). Again, increase of GPx activity after HCV clearance was widely observed in all sub-groups (Suppl. Table 1), and as observed for lipid peroxidation markers, $\Delta$ change of GPx activity was greater in patients with cirrhosis compared to F3 (Suppl. Table 1). HCV eradication led also to lower serum levels of total thiols $(17.22$ [10.66; 28.44] vs 3.34 [2.41; 4.91] $\mathrm{nmol} / \mu \mathrm{l}, \mathrm{P}<0.0001)$ in the whole cohort (Figure 1) and this result was confirmed in patients with F3 or F4 and in all subgroups (Suppl. Table 1). By simple linear regression, GPx activity was inversely associated with $\mathrm{LOOH}$ at baseline $(r=-0.24, \mathrm{P}<0.05)$ and SVR $(r=-0.29, P<0.01)$, indicating the existence of a LOOH/GPx co-regulation in health and disease.

As concern nucleic acid oxidative damage, serum 8-OHdG at baseline were lowered following HCV eradication (558.9 [321.0; 6301.2] vs 294.5 [215.3; 408.95] pg/ml, 
$\mathrm{P}<0.0001)$ (Figure 1). The reduction of $8-\mathrm{OHdG}$ was observed across subgroups with various statistical strength (Suppl. Table 1). We also measured 3-NT levels as markers of protein oxidation/nitrosylation. However, SVR did not significantly change 3-NT levels (799.8 [419.5; 1287.1] vs $821.2[539.6 ; 1201.6] \mathrm{nmol} / \mathrm{I}, \mathrm{P}=0.74)$ neither in the whole cohort (Figure 1) or in the subgroups (Suppl. Table 1), thus showing that the role of protein oxidative/nitrosative stress is less relevant in this context.

\section{Association of oxidative stress with clinical parameters and outcomes}

Levels of lipid peroxidation were proportional to the severity of fibrosis, as showed by higher serum $\mathrm{F}_{2}$-Isoprostanes and $\mathrm{LOOH}$ in patients with F4 compared to F3 (1494 [420.2; $2435]$ vs $428.1[112.4 ; 1167] \mathrm{pg} / \mathrm{ml}, \mathrm{P}<0.05)$ and $(17.3[22.0 ; 7.94]$ vs $9.7[19.9 ; 5.8]$ $\mathrm{nmol} / \mathrm{\mu l}, \mathrm{P}<0.05)$ respectively. In a logistic regression model including all baseline oxidative stress parameters, adjusted for age, log-transformed $F_{2}$-isoprostanes were independently associated with the presence of esophageal varices (OR 3.7 [1.42; 9.62]) (Table 3).

In a logistic regression analysis including all oxidative stress parameters at baseline and considering cIMT $\geq 0.9$ as categorical variable, log-transformed values of $F_{2}$-Isoprostanes were also independently associated with the presence of cIMT $\geq 0.9$ (OR 0.32 [0.08; 1.24], $\mathrm{P}<0.05)$ (Suppl. Table 2) whereas in a logistic regression model evaluating the risk of carotid plaque, log-transformed values of $\mathrm{LOOH}$ were associated with its presence (OR 1.61 [0.75; 3.43], P<0.05) (Suppl. Table 3).

Finally, the most important aim of the study was to evaluate whether changes of any of the assessed oxidative stress parameters was associated with reduction of cIMT. As showed in Table 4, in a multiple linear regression model including changes $(\Delta)$ of the six oxidative stress with changes of cIMT, $\Delta \mathrm{F}_{2}$-Isoprostanes was independently and directly associated with $\Delta$ cIMT $(\beta: 1.746[0.948 ; 2.543], P<0.0001)$, indicating that the higher is the reduction of circulating $\mathrm{F}_{2}$-Isoprostanes, the higher is the reduction of cIMT. 


\section{DISCUSSION}

In this study we aimed to establish whether improvement of cardiovascular outcomes following HCV eradication may be linked to reduction of systemic oxidative stress and demonstrated that the decrease of carotid intima-media thickness after viral clearance is independently associated with the decrease of circulating $\mathrm{F}_{2}$-isoprostanes.

$F_{2}$-isoprostanes are prostaglandin-like compounds that can be formed via a non-enzymatic free radical-initiated peroxidation of arachidonic acid ${ }^{15}$. Besides being considered the most accurate and popular marker of lipid peroxidation ${ }^{24}, \mathrm{~F}_{2}$-isoprostanes plays a role in several pathological process including liver fibrogenesis. In a rat model of carbon tetrachloride-induced hepatic fibrosis, plasma levels of $F_{2}$-isoprostanes progressively increase from fibrosis to cirrhosis and correlate with hepatic collagen content 25 . Furthermore, in vitro studies demonstrated that treatment of hepatic stellate cells (HSCs) with $\mathrm{F}_{2}$-isoprostanes stimulate their activation to myofibroblasts ${ }^{25}$ and these effects are mediated by activation of receptors analogous to those for thromboxane A2 expressed on HSCs ${ }^{26,27}$.

$F_{2}$-isoprostanes show also potent vascular effects including vasoconstriction, monocyte adhesion to the endothelium, platelet aggregation and smooth muscular cells proliferation 17, indicating that they are crucially involved in the atherosclerosis process. In agreement with HSC data, studies in animal models of atherosclerosis demonstrated that $F_{2^{-}}$ isoprostanes can directly promote atherogenesis by activating the thromboxane A2 receptor 28; consistently, the regression of atherosclerotic lesions is accompanied by reduction of $\mathrm{F}_{2}$-isoprostanes ${ }^{29}$. In addition to pre-clinical evidence, clinical data report that $F_{2}$-isoprostanes are tightly associated to carotid atherosclerosis ${ }^{30,31}$.

Overall, on the basis of our results and data reported in literature, we suggest that circulating $\mathrm{F}_{2}$-isoprostanes generated by lipid peroxidation in hepatocytes during chronic $\mathrm{HCV}$ infection can exert fibrogenic effects in the liver and once released in the 
bloodstream can trigger vascular processes associated with onset and progression of atherosclerosis (Figure 2). Activation of thromboxane A2 receptor could be envisioned as the biologic link between the events occurring in liver and vasculature, leading to liver fibrosis and atherogenesis, respectively.

Among other oxidative stress mechanisms described so far in chronic HCV infection, lipid peroxidation has been usually reported in patients by measuring levels of reactive aldehydes as biomarkers ${ }^{11}$. To our knowledge, De Maria et al. and Barbaro et al. were the first that, by biochemical analysis, showed higher malondialdehyde (MDA) respectively in serum and liver of $\mathrm{CHC}$ patients compared to healthy subjects ${ }^{32,33}$. However, a first direct demonstration of the link between lipid peroxidation and fibrosis came from the study of Paradis et al. who reported that higher levels of MDA-protein adducts, as assessed semiquantitatively by immunohistochemistry, were associated with higher stages of fibrosis in liver sections of HCV-infected patients ${ }^{34}$.

In our study we evaluated changes of $\mathrm{LOOH}$, which are organic hydroperoxides, derived by peroxidation of membrane- and lipoprotein-bound lipids, that may damage other macromolecules, thus inducing cell dysfunction and death ${ }^{35}$. Togashi et al. showed higher hepatic LOOH levels compared to healthy controls, proportionally to histological severity of $\mathrm{CHC}{ }^{36}$. Furthermore, $\mathrm{LOOH}$ have been demonstrated to promote carcinogenesis in a mouse model of HCV-hepatocellular carcinoma ${ }^{37}$. LOOH are selectively reduced by GPx4, a monomeric protein belonging to the family of selenocysteine peroxidases ${ }^{38}$, that is down-regulated by $\mathrm{HCV}$ in vitro ${ }^{39}$. $\mathrm{LOOH}$ are reactive species that if not efficiently reduced by GPx4 may undergo further conversion to reactive aldehydes ${ }^{35}$, which have been shown to activate the signaling cascade leading to fibrosis in HCV ${ }^{40}$. Here we showed that the LOOH/GPx axis is clinically evident in CHC. GPx activity has been already demonstrated to be lower in patients with $\mathrm{CHC}$ compared to healthy individuals 41,42 and in vitro data show that GPx exert protective anti-HCV effects ${ }^{43-45}$. 
Finally, we would like to point out the importance of a marked reduction of 8-OHdG following HCV-eradication in our cohort. Beside lipid peroxidation, another feature of $\mathrm{CHC}$ is the presence of oxidative DNA damage, as assessed by the marker $8-\mathrm{OHdG}$ that previous studies showed to be higher in the liver of patients with $\mathrm{CHC}$ compared with controls ${ }^{46-48}$. From a clinical point of view, $8-O H d G$ expression has been showed to be an independent predictor of HCC development ${ }^{49}$. For this reason, our results of a ten-fold decrease of 8-OHdG after viral clearance can partly explain the lower incidence of HCC following DAA treatment ${ }^{50}$.

Our study has some limits. Oxidative stress was not measured on liver samples because it was not ethically possible a follow-up biopsy; however, we used well-characterized biomarkers of lipid, protein, and nucleic acid damage. Furthermore, serum GPx activity was measured without discriminating between the different isoforms; nonetheless, since GPx4 displays a reducing activity specific for $\mathrm{LOOH}$ we are confident that our results reflect GPx4. Another limitation lies in the lack of data about the impact of HCV eradication on oxidative stress in patients with $\mathrm{HCV}$ infection and milder liver fibrosis. Finally, despite we adjusted for variables that may confound results, we cannot rule out the existence of potential residual confounding.

In conclusion, our study demonstrated an independent and direct association between reduction of subclinical atherosclerosis and reduction of $F_{2}$-isoprostanes after viral clearance that may provide a molecular rationale explaining improvement of cardiovascular outcomes following SVR. 
Table 1. General features of the study population $(n=105)$

\begin{tabular}{|c|c|}
\hline Parameter (units) & \\
\hline Age $(y)$ & $62.4 \pm 11.2$ \\
\hline Males (n) & $62(59 \%)$ \\
\hline F3/cirrhosis (n) & $53 / 52$ \\
\hline Child-Pugh-Turcotte score A5/A6 (n) & $27 / 25$ \\
\hline F1 esophageal varices $(n)$ & 26 \\
\hline Genotype 1a/1b/2/3/4 (n) & $12 / 79 / 5 / 5 / 4$ \\
\hline $\begin{array}{l}\text { OMB/PAR/RIT/DAS } \pm R B V, S O F / L E D \pm R B V \\
\text { SOF+DAC } \pm \text { RBV, }\end{array}$ & $60,24,9,7,4,1$ \\
\hline Diabetes (n) & $13(12 \%)$ \\
\hline Arterial hypertension $(\mathrm{n})$ & $32(30 \%)$ \\
\hline Smoking & $16(15 \%)$ \\
\hline Subclinical atherosclerosis & $76(72 \%)$ \\
\hline
\end{tabular}


Table 2. Changes in clinical parameters at SVR after DAA treatment $(n=105)$

\begin{tabular}{|c|c|c|c|}
\hline Parameter (units) & Baseline & SVR12 & $\mathbf{P}$ \\
\hline Body weight (kg) & $74.6 \pm 14.2$ & $74.8 \pm 13.8$ & NS \\
\hline HCV-RNA (U/ml) & $\begin{array}{l}950000(317250 ; \\
1740000)\end{array}$ & Undetectable & $<0.0001$ \\
\hline AST (U/I) & $46(28.75 ; 74.5)$ & $20(17 ; 26)$ & $<0.0001$ \\
\hline $\operatorname{ALT}(\mathrm{U} / \mathrm{I})$ & $58.5(30 ; 89)$ & $20(14.75 ; 26.25)$ & $<0.0001$ \\
\hline GGT (U/I) & $43.5(27 ; 90.25)$ & $21(16.75 ; 34.75)$ & $<0.0001$ \\
\hline Total bilirubin (mg/dl) & $0.77(0.5 ; 1)$ & $0.7(0.42 ; 1)$ & NS \\
\hline Direct bilirubin (mg/dl) & $0.34(0.2 ; 0.44)$ & $0.24(0.2 ; 0.35)$ & 0.01 \\
\hline INR & $1(0.96 ; 1)$ & $1(1 ; 1.1)$ & NS \\
\hline Albumin (g/dl) & $4.0(3.8 ; 4.2)$ & $4.1(3.9 ; 4.3)$ & $<0.05$ \\
\hline Platelet count $\left(10^{3} / \mu \mathrm{l}\right)$ & $139 \pm 61$ & $160 \pm 72$ & $<0.05$ \\
\hline $\begin{array}{l}\text { Fasting plasma } \\
\text { glucose (mg/dl) }\end{array}$ & $98(88 ; 108)$ & $94(86.5 ; 104)$ & $<0.05$ \\
\hline $\begin{array}{l}\text { Total cholesterol } \\
(\mathrm{mg} / \mathrm{dl})\end{array}$ & $156 \pm 40$ & $168 \pm 44$ & $<0.05$ \\
\hline $\begin{array}{l}\text { Triglycerides } \\
(\mathrm{mg} / \mathrm{dl})\end{array}$ & $85.1 \pm 31.7$ & $94.0 \pm 40.5$ & $<0.05$ \\
\hline Creatinine (mg/dl) & $0.8(0.7 ; 0.9)$ & $0.8(0.7 ; 0.9)$ & NS \\
\hline Liver stiffness $(\mathrm{kPa})$ & $12(10.1 ; 19.4)$ & $10.6(6.7 ; 17)$ & $<0.0001$ \\
\hline $\begin{array}{l}\text { Intima-media } \\
\text { thickness (mm) }\end{array}$ & $0.92 \pm 0.20$ & $0.83 \pm 0.21$ & $<0.001$ \\
\hline
\end{tabular}

Results are expressed as mean \pm SD or median IQR based on data distribution and consistently $\mathrm{P}$ are calculated by paired T-test or Wilcoxon test, respectively. 
Table 3. Multivariable logistic regression analysis, adjusted for age, between baseline oxidative stress parameters (exposure) and the risk of esophageal varices (outcome).

\begin{tabular}{|l|c|c|}
\hline $\begin{array}{l}\text { Parameter } \\
\text { (log-transformed) }\end{array}$ & OR (95\% Cl) & P \\
\hline F$_{\text {-isoprostanes }}$ & $8.76(1.8 ; 42.7)$ & $\mathbf{0 . 0 0 7}$ \\
\hline LOOH & $0.27(0.07 ; 1.01)$ & 0.05 \\
\hline GPx activity & $0.74(0.31 ; 1.77)$ & 0.495 \\
\hline Total thiols & $0.59(0.25 ; 1.4)$ & 0.232 \\
\hline 8-OHdG & $0.46(0.17 ; 1.3)$ & 0.146 \\
\hline 3-NT & $0.76(0.34 ; 1.69)$ & 0.505 \\
\hline
\end{tabular}

${ }^{*}$ reported per standard deviation increase in oxidative stress parameters. LOOH, lipid hydroperoxides; 8-OHdG, 8-hydroxy-2'-deoxyguanosine; GPx, gluthatione peroxidase; 3-NT, 3nitrotyrosine

Table 4. Multivariable linear regression analysis, adjusted for age, baseline exposure and baseline outcome, between $\Delta$ oxidative stress (exposure) and $\Delta$ cIMT (outcome)

\begin{tabular}{|c|c|c|}
\hline$\Delta$ Parameter & $\boldsymbol{\beta}(\mathbf{9 5 \%} \mathrm{Cl})$ & $\mathbf{P}$ \\
\hline F $_{2}$-isoprostanes & $1.746(0.948 ; 2.543)$ & $<0.0001$ \\
\hline LOOH & $0.368(-0.139 ; 0.874)$ & 0.151 \\
\hline GPx activity & $-0.042(-0.377 ; 0.294)$ & 0.805 \\
\hline Total thiols & $0.114(-0.335 ; 0.563)$ & 0.938 \\
\hline 8-OHdG & $-0.058(-1.544 ; 1.429)$ & 0.542 \\
\hline 3-NT & $-2.22(-9.453 ; 5.012)$ & 0.614 \\
\hline
\end{tabular}

Results are expressed as standardized beta coefficients with $95 \% \mathrm{Cl}$. $\mathrm{LOOH}$, lipid hydroperoxides; 8-OHdG, 8-hydroxy-2'-deoxyguanosine; GPx, gluthatione peroxidase; 3-NT, 3-nitrotyrosine 
Suppl. Table 1. Changes in oxidative stress parameters at sustained virologic response (SVR) after DAA treatment in subgroups discriminated according to fibrosis, blood glucose, and BMI

\begin{tabular}{|c|c|c|c|}
\hline \multirow{2}{*}{ Parameter (units) } & \multicolumn{3}{|c|}{ F3 fibrosis $(n=53)$} \\
\hline & Baseline & SVR & $\mathbf{P}$ \\
\hline $\begin{array}{c}F_{2} \text {-isoprostanes } \\
(\mathrm{pg} / \mathrm{ml})\end{array}$ & $428.1[112.4 ; 1167]$ & $144.6[67.5 ; 505.2]$ & $<0.05$ \\
\hline $\mathrm{LOOH}(\mathrm{nmol} / \mu \mathrm{l})$ & $9.67[5.84 ; 19.9]$ & $5.7[2.25 ; 10.9]$ & $<0.01$ \\
\hline $\begin{array}{l}\text { GPx activity } \\
(\mathrm{nmol} / \mathrm{min} / \mathrm{ml})\end{array}$ & $10.4[5.3 ; 16.3]$ & $12.7[8.7 ; 20.6]$ & $<0.05$ \\
\hline 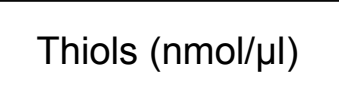 & $18.4[11.4 ; 33.4]$ & $3.2[2.2 ; 5.1]$ & $<0.0001$ \\
\hline 8-OHdG (pg/ml) & $4018[343 ; 7720]$ & $283.8[183 ; 403]$ & $<0.0001$ \\
\hline \multirow[t]{3}{*}{ 3-NT (nmol/l) } & $863[432 ; 1251]$ & $822[540 ; 1254]$ & NS \\
\hline & \multicolumn{3}{|c|}{ Compensated cirrhosis $(n=52)$} \\
\hline & Baseline & SVR & $\mathbf{P}$ \\
\hline $\begin{array}{c}F_{2-\text { isoprostanes }} \\
(\mathrm{pg} / \mathrm{ml})\end{array}$ & $1494[420 ; 2435]$ & $90.0[53.9 ; 188]$ & $<0.0001$ \\
\hline $\mathrm{LOOH}(\mathrm{nmol} / \mu \mathrm{l})$ & $17.3[7.94 ; 22]$ & $4.8[2.5 ; 7.8]$ & $<0.0001$ \\
\hline $\begin{array}{l}\text { GPx activity } \\
\text { (nmol/min/ml) }\end{array}$ & $7.6[3.57 ; 15.3]$ & $15.5[10.1 ; 22.2]$ & $<0.0001$ \\
\hline Thiols $(\mathrm{nmol} / \mu \mathrm{l})$ & $16.7[9.3 ; 21.7]$ & $3.4[2.5 ; 4.96]$ & $<0.0001$ \\
\hline 8-OHdG (pg/ml) & $456.7[249 ; 804]$ & $309.5[240 ; 438]$ & $<0.05$ \\
\hline 3-NT (nmol/l) & $741[391 ; 1580]$ & 801 [495; 1157] & NS \\
\hline
\end{tabular}

LOOH, lipid hydroperoxides; GPx, glutathione peroxidase; 8-OHdG, 8-hydroxy-2'-deoxyguanosine; 3-NT, 3-nitrotyrosine 


\begin{tabular}{|c|c|c|c|}
\hline \multirow{2}{*}{ Parameter (units) } & \multicolumn{3}{|c|}{ Blood glucose $<100 \mathrm{mg} / \mathrm{dl}(\mathrm{n}=70)$} \\
\hline & Baseline & SVR & $\mathbf{P}$ \\
\hline $\begin{array}{c}F_{2} \text {-isoprostanes } \\
(\mathrm{pg} / \mathrm{ml})\end{array}$ & $596[114 ; 1913]$ & $129[60 ; 338]$ & 0.0005 \\
\hline $\mathrm{LOOH}(\mathrm{nmol} / \mu \mathrm{l})$ & $14.1[6.1 ; 20.1]$ & $4.8[2.3 ; 9.4]$ & $<0.0005$ \\
\hline $\begin{array}{l}\text { GPx activity } \\
(\mathrm{nmol} / \mathrm{min} / \mathrm{ml})\end{array}$ & $11.2[4.6 ; 16.4]$ & $13.2[8.5 ; 19.2]$ & $<0.05$ \\
\hline Thiols (nmol/ul) & $18.4[10.7 ; 31.0]$ & $3.2[2.5 ; 4.4]$ & $<0.0001$ \\
\hline 8-OHdG (pg/ml) & $815.4[381.5 ; 7888]$ & 319 [218; 449] & $<0.0001$ \\
\hline \multirow[t]{3}{*}{ 3-NT (nmol/l) } & $892[432 ; 1785]$ & $827[563 ; 1261]$ & NS \\
\hline & \multicolumn{3}{|c|}{ Blood glucose $\geq 100 \mathrm{mg} / \mathrm{dl}(\mathrm{n}=35)$} \\
\hline & Baseline & SVR & $\mathbf{P}$ \\
\hline $\begin{array}{c}F_{2-\text { isoprostanes }} \\
(\mathrm{pg} / \mathrm{ml})\end{array}$ & 795 [200; 2023] & $108[61 ; 522]$ & 0.001 \\
\hline $\mathrm{LOOH}(\mathrm{nmol} / \mu \mathrm{l})$ & $12.5[6.5 ; 20.9]$ & $6[2.3 ; 9.7]$ & 0.0005 \\
\hline $\begin{array}{l}\text { GPx activity } \\
(\mathrm{nmol} / \mathrm{min} / \mathrm{ml})\end{array}$ & $8.9[4.1 ; 14.1]$ & $15.7[11.9 ; 21.9]$ & $<0.001$ \\
\hline 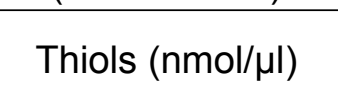 & $15.1[9.9 ; 24.2]$ & $3.5[1.8 ; 5.9]$ & $<0.0001$ \\
\hline 8-OHdG (pg/ml) & 362 [183; 3018] & 283 [188; 355] & $<0.05$ \\
\hline 3-NT (nmol/l) & 732 [332; 1213] & $768[453 ; 1140]$ & NS \\
\hline
\end{tabular}




\begin{tabular}{|c|c|c|c|}
\hline \multirow{2}{*}{ Parameter (units) } & \multicolumn{3}{|c|}{ BMI $<25 \mathrm{~kg} / \mathrm{m}^{2}(\mathrm{n}=79)$} \\
\hline & Baseline & SVR & $\mathbf{P}$ \\
\hline $\begin{array}{c}\mathrm{F}_{2 \text {-isoprostanes }} \\
(\mathrm{pg} / \mathrm{ml})\end{array}$ & 636 [148; 1923] & $130[67.6 ; 496]$ & $<0.0001$ \\
\hline $\mathrm{LOOH}(\mathrm{nmol} / \mu \mathrm{l})$ & $13.9[6.3 ; 20.7]$ & $5.3[2.3 ; 10.3]$ & $<0.0001$ \\
\hline $\begin{array}{l}\text { GPx activity } \\
(\mathrm{nmol} / \mathrm{min} / \mathrm{ml})\end{array}$ & $9.8[4.0 ; 16.6]$ & $13.4[8.9 ; 20.8]$ & $<0.005$ \\
\hline Thiols (nmol/ $/ \mu \mathrm{l})$ & $17.3[11.3 ; 30.7]$ & $3.1[2.1 ; 4.3]$ & $<0.0001$ \\
\hline 8-OHdG (pg/ml) & 642 [296; 7167] & 294.5 [200; 389] & $<0.0001$ \\
\hline \multirow[t]{3}{*}{ 3-NT (nmol/l) } & $912[414 ; 1278]$ & $896[266 ; 1233]$ & NS \\
\hline & \multicolumn{3}{|c|}{$\mathrm{BMI} \geq 25 \mathrm{~kg} / \mathrm{m}^{2}(\mathrm{n}=26)$} \\
\hline & Baseline & SVR & $\mathbf{P}$ \\
\hline $\begin{array}{c}F_{2-\text { isoprostanes }} \\
(\mathrm{pg} / \mathrm{ml})\end{array}$ & 526 [119; 1793] & 87 [47.6; 379] & $<0.01$ \\
\hline $\mathrm{LOOH}(\mathrm{nmol} / \mu \mathrm{l})$ & $10.2[5.8 ; 21.8]$ & $4.6[2.6 ; 7.7]$ & 0.005 \\
\hline $\begin{array}{l}\text { GPx activity } \\
(\mathrm{nmol} / \mathrm{min} / \mathrm{ml})\end{array}$ & $10.8[14.3 ; 5.0]$ & $16.4[11.3 ; 21.1]$ & $<0.05$ \\
\hline Thiols (nmol/ $/ \mu \mathrm{l})$ & $15.1[9.8 ; 25.6]$ & $4.0[2.9 ; 5.2]$ & $<0.0001$ \\
\hline 8-OHdG (pg/ml) & 379 [307; 4239] & $304[224 ; 511]$ & $<0.05$ \\
\hline 3-NT (nmol/l) & 732 [394; 1911] & $663[421 ; 887]$ & NS \\
\hline
\end{tabular}


Suppl. Table 2. Multivariable logistic regression analysis, adjusted for age, between oxidative stress parameters at baseline (exposure) and the risk of clMT $\geq 0.9$ (outcome)

\begin{tabular}{|l|c|c|}
\hline $\begin{array}{l}\text { Parameter } \\
\text { (log-transformed) }\end{array}$ & OR (95\% CI) & P \\
\hline F-isoprostanes & $0.32(0.08 ; 1.24)$ & $\mathbf{0 . 0 4 7}$ \\
\hline LOOH & $1(0.43 ; 2.33)$ & 0.324 \\
\hline GPx activity & $0.63(0.26 ; 1.54)$ & 0.798 \\
\hline Total thiols & $0.34(0.12 ; 1.01)$ & 0.139 \\
\hline 8-OHdG & $1.17(0.46 ; 2.97)$ & 0.783 \\
\hline 3-NT & $0.71(0.24 ; 2.11)$ & 0.784 \\
\hline
\end{tabular}

"reported per standard deviation increase in oxidative stress parameter. $\mathrm{LOOH}$, lipid hydroperoxides; 8-OHdG, 8-hydroxy-2'-deoxyguanosine; GPx, gluthatione peroxidase; 3-NT, 3-nitrotyrosine

Suppl. Table 3. Multivariable logistic regression analysis, adjusted for age, between oxidative stress parameters at baseline (exposure) and the risk of carotid plaque (outcome)

\begin{tabular}{|l|c|c|}
\hline $\begin{array}{l}\text { Parameter } \\
\text { (log-transformed) }\end{array}$ & OR $(95 \% \mathbf{C l})^{*}$ & P \\
\hline F-isoprostanes & $0.75(0.36 ; 1.58)$ & 0.10 \\
\hline LOOH & $1.61(0.75 ; 3.43)$ & $\mathbf{0 . 0 3}$ \\
\hline GPx activity & $1.06(0.59 ; 1.91)$ & 0.50 \\
\hline Total thiols & $1.27(0.72 ; 2.24)$ & 0.46 \\
\hline 8-OHdG & $1.51(0.7 ; 3.22)$ & 0.90 \\
\hline 3-NT & $1.14(0.65 ; 2.03)$ & 0.14 \\
\hline
\end{tabular}

"reported per standard deviation increase in oxidative stress parameter. $\mathrm{LOOH}$, lipid hydroperoxides; 8-OHdG, 8-hydroxy-2'-deoxyguanosine; GPx, gluthatione peroxidase; 3-NT, 3-nitrotyrosine 
Figure 1. Effects of HCV eradication following DAA on oxidative stress parameters.

Results are showed as median with $95 \% \mathrm{Cl}, \mathrm{n}=105 . \mathrm{P}$ is calculated by Wilcoxon test because all parameters had a non-normal distribution both at baseline and at follow-up. LOOH, lipid hydroperoxides; GPx, glutathione peroxidase; 8-OHdG, 8-hydroxy-2'-deoxyguanosine; 3-NT, 3nitrotyrosine.
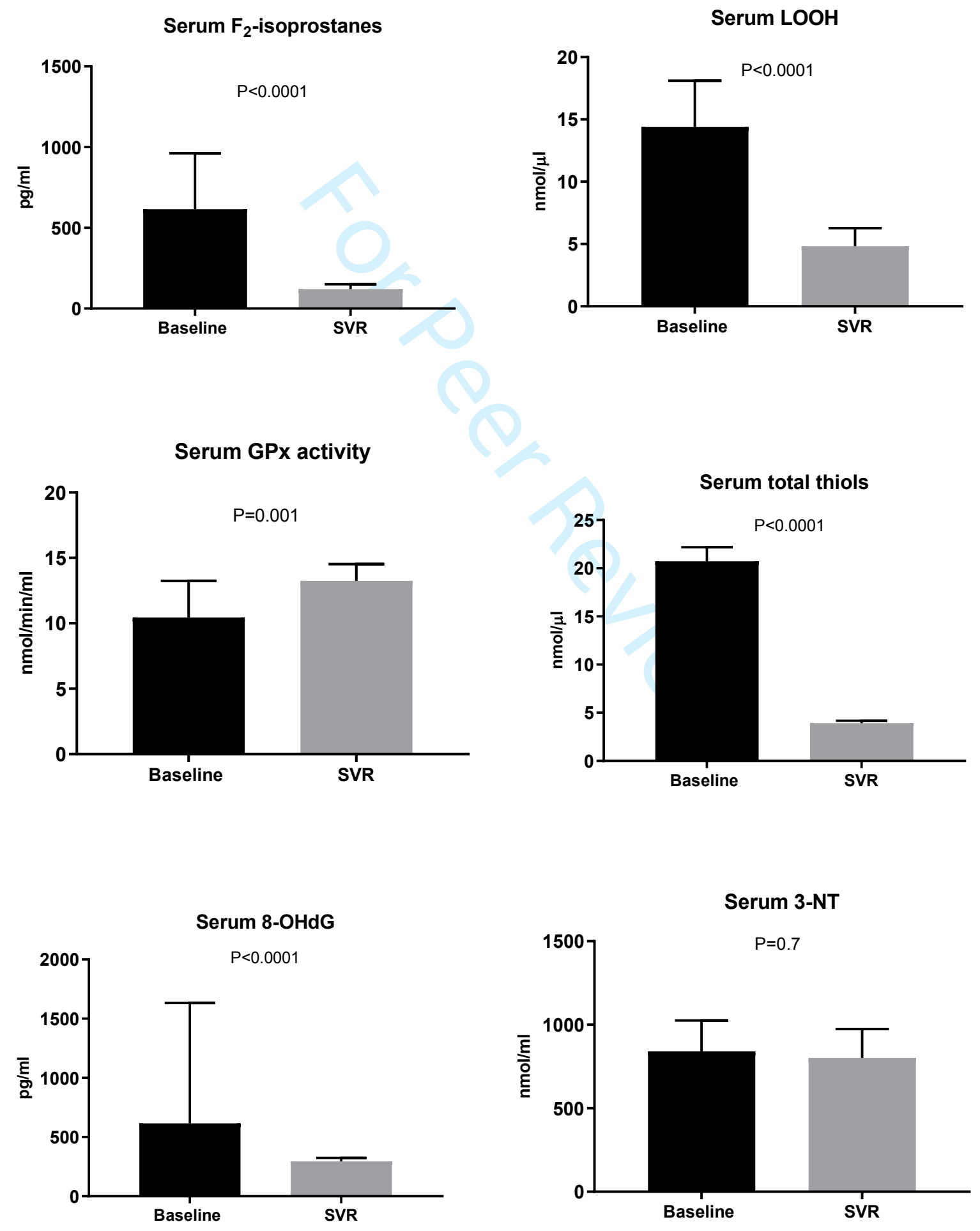
Figure 2. Plausible mechanisms by which oxidative stress produced in the liver during chronic hepatitis $\mathrm{C}$ promotes atherosclerosis. HCV infection induces free radical production that leads to peroxidation of lipid macromolecules in the hepatocyte and thus to overproduction of lipid hydroperoxides and in particular of $\mathrm{F}_{2}$-isoprostanes.

$F_{2}$-isoprostanes exert fibrogenic effects locally by stimulating hepatic stellate cells (HSC) and once released in the bloodstream exert atherogenic effects. $F_{2}$-isoprostanes bind to the thromboxane A2 receptor on the endothelium promoting vasoconstriction, monocyte aggregation and smooth muscular cells proliferation. HCV eradication interrupts this vicious cycle by reduction of circulating $F_{2}$-isoprostanes

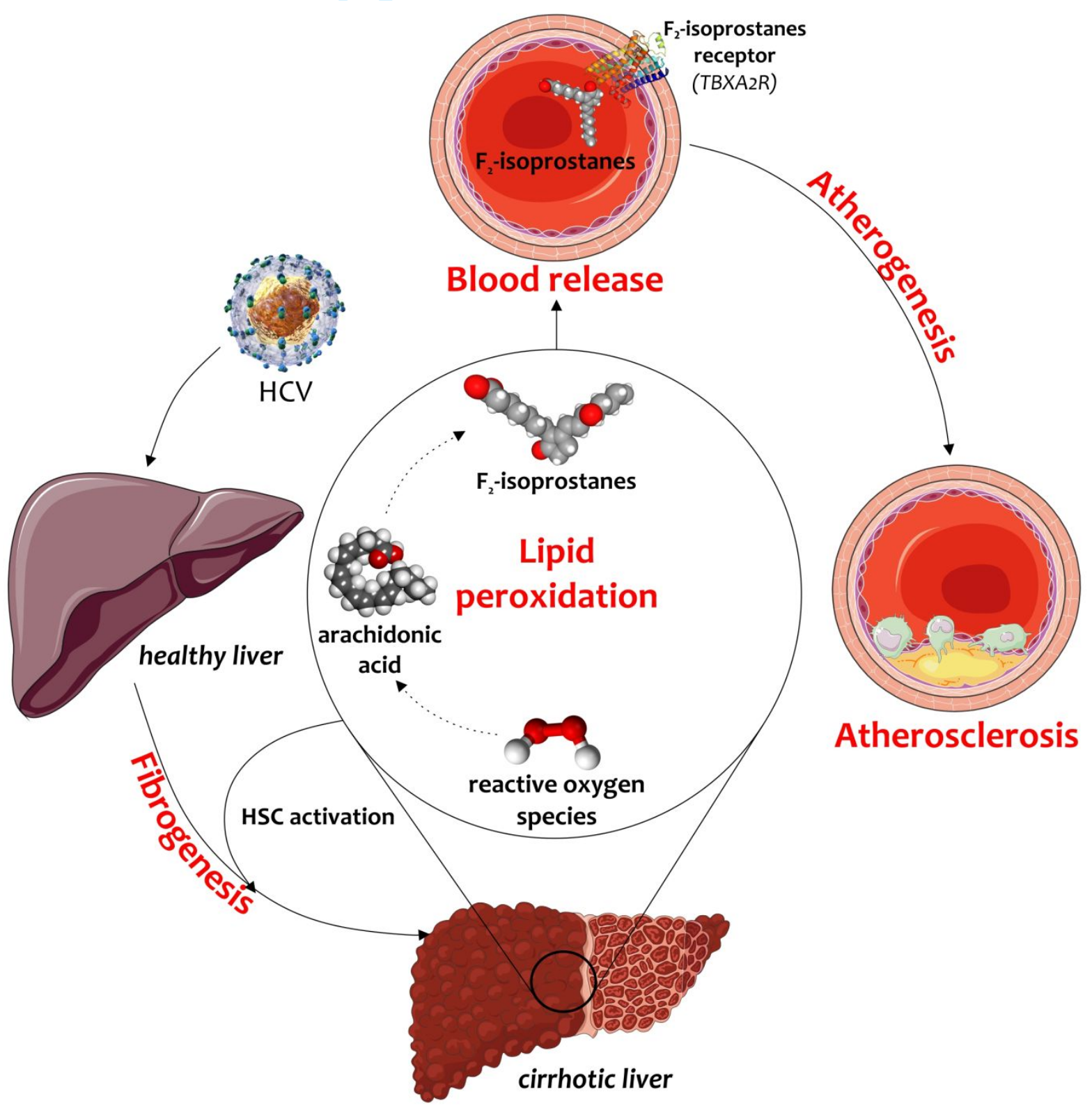




\section{REFERENCES}

1. Polaris Observatory HCVC. Global prevalence and genotype distribution of hepatitis C virus infection in 2015: a modelling study. Lancet Gastroenterol Hepatol. 2017;2(3):161-176.

2. Soverini V, Persico M, Bugianesi E, et al. HBV and HCV infection in type 2 diabetes mellitus: a survey in three diabetes units in different Italian areas. Acta diabetologica. 2011;48(4):337-343.

3. Salomone F, Catania M, Montineri A, et al. Hepatitis C virus eradication by direct antiviral agents improves glucose tolerance and reduces post-load insulin resistance in nondiabetic patients with genotype 1. Liver international : official journal of the International Association for the Study of the Liver. 2018;38(7):1206-1211.

4. Petta S, Maida M, Macaluso FS, et al. Hepatitis C Virus Infection Is Associated With Increased Cardiovascular Mortality: A Meta-Analysis of Observational Studies. Gastroenterology. 2016;150(1):145-155 e144; quiz e115-146.

5. Ioannou GN, Feld JJ. What Are the Benefits of a Sustained Virologic Response to DirectActing Antiviral Therapy for Hepatitis C Virus Infection? Gastroenterology. 2019;156(2):446-460 e442.

6. Adinolfi LE, Petta S, Fracanzani AL, et al. Impact of hepatitis $\mathrm{C}$ virus clearance by directacting antiviral treatment on the incidence of major cardiovascular events: A prospective multicentre study. Atherosclerosis. 2020;296:40-47.

7. Sies H. Oxidative stress: a concept in redox biology and medicine. Redox Biol. 2015;4:180-183.

8. Pal VK, Bandyopadhyay P, Singh A. Hydrogen sulfide in physiology and pathogenesis of bacteria and viruses. IUBMB Life. 2018;70(5):393-410.

9. Ursini F, Maiorino M, Forman HJ. Redox homeostasis: The Golden Mean of healthy living. Redox Biol. 2016;8:205-215.

10. Medvedev R, Ploen D, Hildt E. HCV and Oxidative Stress: Implications for HCV Life Cycle and HCV-Associated Pathogenesis. Oxid Med Cell Longev. 2016;2016:9012580.

11. Ivanov AV, Bartosch B, Smirnova OA, Isaguliants MG, Kochetkov SN. HCV and oxidative stress in the liver. Viruses. 2013;5(2):439-469.

12. Valgimigli L, Valgimigli M, Gaiani S, Pedulli GF, Bolondi L. Measurement of oxidative stress in human liver by EPR spin-probe technique. Free Radic Res. 2000;33(2):167178.

13. Valgimigli M, Valgimigli L, Trere D, et al. Oxidative stress EPR measurement in human liver by radical-probe technique. Correlation with etiology, histology and cell proliferation. Free Radic Res. 2002;36(9):939-948.

14. Cipak Gasparovic A, Zarkovic N, Zarkovic K, et al. Biomarkers of oxidative and nitrooxidative stress: conventional and novel approaches. Br J Pharmacol. 2017;174(12):1771-1783.

15. Galano JM, Lee YY, Oger C, et al. Isoprostanes, neuroprostanes and phytoprostanes: An overview of 25years of research in chemistry and biology. Progress in lipid research. 2017;68:83-108.

16. Comporti M, Arezzini B, Signorini C, Vecchio D, Gardi C. Oxidative stress, isoprostanes and hepatic fibrosis. Histology and histopathology. 2009;24(7):893-900.

17. Bauer J, Ripperger A, Frantz S, Ergun S, Schwedhelm E, Benndorf RA. Pathophysiology of isoprostanes in the cardiovascular system: implications of isoprostane-mediated thromboxane A2 receptor activation. British journal of pharmacology.

2014;171(13):3115-3131. 
18. Petta S, Adinolfi LE, Fracanzani AL, et al. Hepatitis $C$ virus eradication by direct-acting antiviral agents improves carotid atherosclerosis in patients with severe liver fibrosis. Journal of hepatology. 2018;69(1):18-24.

19. Williams B, Mancia G, Spiering W, et al. 2018 ESC/ESH Guidelines for the management of arterial hypertension. European heart journal. 2018;39(33):3021-3104.

20. Di Giacomo C, Acquaviva R, Sorrenti V, et al. Oxidative and antioxidant status in plasma of runners: effect of oral supplementation with natural antioxidants. J Med Food. 2009;12(1):145-150.

21. Poulsen HE, Nadal LL, Broedbaek K, Nielsen PE, Weimann A. Detection and interpretation of 8-oxodG and 8-oxoGua in urine, plasma and cerebrospinal fluid. Biochim Biophys Acta. 2014;1840(2):801-808.

22. Teixeira D, Fernandes R, Prudencio C, Vieira M. 3-Nitrotyrosine quantification methods: Current concepts and future challenges. Biochimie. 2016;125:1-11.

23. European Association for the Study of the Liver. Electronic address eee. EASL Recommendations on Treatment of Hepatitis C 2016. J Hepatol. 2017;66(1):153-194.

24. van 't Erve TJ, Kadiiska MB, London SJ, Mason RP. Classifying oxidative stress by F2isoprostane levels across human diseases: A meta-analysis. Redox biology. 2017;12:582-599.

25. Comporti M, Arezzini B, Signorini C, Sgherri C, Monaco B, Gardi C. F2-isoprostanes stimulate collagen synthesis in activated hepatic stellate cells: a link with liver fibrosis? Laboratory investigation; a journal of technical methods and pathology. 2005;85(11):1381-1391.

26. Gardi C, Arezzini B, Monaco B, De Montis MG, Vecchio D, Comporti M. F2-isoprostane receptors on hepatic stellate cells. Laboratory investigation; a journal of technical methods and pathology. 2008;88(2):124-131.

27. Acquaviva A, Vecchio D, Arezzini B, Comporti M, Gardi C. Signaling pathways involved in isoprostane-mediated fibrogenic effects in rat hepatic stellate cells. Free radical biology \& medicine. 2013;65:201-207.

28. Tang M, Cyrus T, Yao Y, Vocun L, Pratico D. Involvement of thromboxane receptor in the proatherogenic effect of isoprostane F2alpha-III: evidence from apolipoprotein Eand LDL receptor-deficient mice. Circulation. 2005;112(18):2867-2874.

29. Tangirala RK, Pratico D, FitzGerald GA, et al. Reduction of isoprostanes and regression of advanced atherosclerosis by apolipoprotein E. The Journal of biological chemistry. 2001;276(1):261-266.

30. Yoon JH, Kim JY, Park JK, Ko SB. Oxidative damage markers are significantly associated with the carotid artery intima-media thickness after controlling for conventional risk factors of atherosclerosis in men. PloS one. 2015;10(3):e0119731.

31. Monneret D, Pepin JL, Godin-Ribuot D, et al. Association of urinary 15-F2t-isoprostane level with oxygen desaturation and carotid intima-media thickness in nonobese sleep apnea patients. Free radical biology \& medicine. 2010;48(4):619-625.

32. De Maria N, Colantoni A, Fagiuoli S, et al. Association between reactive oxygen species and disease activity in chronic hepatitis C. Free Radic Biol Med. 1996;21(3):291-295.

33. Barbaro G, Di Lorenzo G, Ribersani M, et al. Serum ferritin and hepatic glutathione concentrations in chronic hepatitis $\mathrm{C}$ patients related to the hepatitis $\mathrm{C}$ virus genotype. J Hepatol. 1999;30(5):774-782.

34. Paradis V, Mathurin $\mathrm{P}$, Kollinger $\mathrm{M}$, et al. In situ detection of lipid peroxidation in chronic hepatitis C: correlation with pathological features. J Clin Pathol. 1997;50(5):401-406.

35. Gaschler MM, Stockwell BR. Lipid peroxidation in cell death. Biochem Biophys Res Commun. 2017;482(3):419-425. 
36. Togashi H, Shinzawa H, Matsuo T, et al. High content of lipid hydroperoxides in livers from patients with chronic hepatitis C. J Med. 2000;31(1-2):3-14.

37. Moriya K, Nakagawa K, Santa T, et al. Oxidative stress in the absence of inflammation in a mouse model for hepatitis C virus-associated hepatocarcinogenesis. Cancer Res. 2001;61(11):4365-4370.

38. Flohe L, Toppo S, Cozza G, Ursini F. A comparison of thiol peroxidase mechanisms. Antioxid Redox Signal. 2011;15(3):763-780.

39. Morbitzer M, Herget T. Expression of gastrointestinal glutathione peroxidase is inversely correlated to the presence of hepatitis $\mathrm{C}$ virus subgenomic RNA in human liver cells. J Biol Chem. 2005;280(10):8831-8841.

40. Parola M, Robino G. Oxidative stress-related molecules and liver fibrosis. J Hepatol. 2001;35(2):297-306.

41. Ko WS, Guo CH, Yeh MS, et al. Blood micronutrient, oxidative stress, and viral load in patients with chronic hepatitis C. World J Gastroenterol. 2005;11(30):4697-4702.

42. Levent $\mathrm{G}$, Ali A, Ahmet A, et al. Oxidative stress and antioxidant defense in patients with chronic hepatitis $\mathrm{C}$ patients before and after pegylated interferon alfa- $2 \mathrm{~b}$ plus ribavirin therapy. J Transl Med. 2006;4:25.

43. Nguyen BN, Okuno Y, Ajiro M, et al. Retinoid derivative Tp80 exhibits anti-hepatitis C virus activity through restoration of GI-GPx expression. J Med Virol. 2017;89(7):12241234.

44. Nourooz-Zadeh J, Tajaddini-Sarmadi J, McCarthy S, Betteridge DJ, Wolff SP. Elevated levels of authentic plasma hydroperoxides in NIDDM. Diabetes. 1995;44(9):1054-1058.

45. Facchini FS, Humphreys MH, DoNascimento CA, Abbasi F, Reaven GM. Relation between insulin resistance and plasma concentrations of lipid hydroperoxides, carotenoids, and tocopherols. Am J Clin Nutr. 2000;72(3):776-779.

46. Shimoda R, Nagashima M, Sakamoto M, et al. Increased formation of oxidative DNA damage, 8-hydroxydeoxyguanosine, in human livers with chronic hepatitis. Cancer Res. 1994;54(12):3171-3172.

47. Farinati F, Cardin R, Degan P, et al. Oxidative DNA damage in circulating leukocytes occurs as an early event in chronic HCV infection. Free Radic Biol Med. 1999;27(1112):1284-1291.

48. Cardin R, Saccoccio G, Masutti F, Bellentani S, Farinati F, Tiribelli C. DNA oxidative damage in leukocytes correlates with the severity of HCV-related liver disease: validation in an open population study. J Hepatol. 2001;34(4):587-592.

49. Chuma M, Hige S, Nakanishi M, et al. 8-Hydroxy-2'-deoxy-guanosine is a risk factor for development of hepatocellular carcinoma in patients with chronic hepatitis $C$ virus infection. J Gastroenterol Hepatol. 2008;23(9):1431-1436.

50. Calvaruso V, Cabibbo G, Cacciola I, et al. Incidence of Hepatocellular Carcinoma in Patients With HCV-Associated Cirrhosis Treated With Direct-Acting Antiviral Agents. Gastroenterology. 2018. 